\title{
Phytophthora nicotianae Infection of Citrus Leaves and Host Defense Activation Compared to Root Infection
}

\author{
Jian Wu, ${ }^{1,2}$ Utpal Handique, ${ }^{1,2}$ James Graham, ${ }^{1}$ and Evan Johnson ${ }^{1, \dagger}$ \\ ${ }^{1}$ Citrus Research and Education Center, University of Florida, 700 Experiment Station Road, Lake Alfred, FL, U.S.A. \\ ${ }^{2}$ Potato Engineering \& Technology Research Center, Inner Mongolia University, 235 University Road, Hohhot, Inner Mongolia, China \\ Accepted for publication 26 March 2020.
}

\begin{abstract}
Currently, little is known about the host pathogen interaction between Phytophthora spp. and citrus roots versus leaves. Therefore, we compared the molecular events occurring in citrus roots and leaves after zoospore inoculation with Phytophthora nicotianae. We analyzed the physical characteristics and genetic responses to $P$. nicotianae infection of leaves and roots for susceptible and tolerant citrus rootstocks to examine the potential for leaves to model root responses to $P$. nicotianae infection. Leaves responded faster and stronger to $P$. nicotianae infection than roots, and leaves showed greater differential response than roots. In addition to differences in hormonal responses, sugar, phospholipase D (PLD), and phospholipase A (PLA) involvement in the interaction between citrus and P. nicotianae was identified. This
\end{abstract}

ABSTRACT

Plants and pathogens interact at the physical, physiological, and molecular level. The interaction has been examined extensively at these different levels with the goal of developing plant resistance or tolerance to pathogen infection (Aragón et al. 2017; Dodds and Rathjen 2010; Dutt et al. 2015; Melotto et al. 2008). Physical structures such as leaf cuticle and root epidermis are the first obstacles that pathogens need to overcome for successful infection (Aragón et al. 2017; De Coninck et al. 2015; Ranathunge et al. 2008). In addition to being physical barriers, these structures also play a role in activating plant defense by recognition of pathogenassociated molecular patterns (PAMPs) by receptor proteins called pattern recognition receptors (PRRs) located at the plant cell surface (Aragón et al. 2017; Dodds and Rathjen 2010; Ju et al. 2017; Nishimura et al. 2003; Reina-Pinto and Yephremov 2009). After successful pathogen penetration, the damage will activate plant immunity by releasing endogenous molecules which are called recognition of damage-associated molecular patterns (DAMPs) (Choi and Klessig 2016; Dodds and Rathjen 2010). Stomata on leaf surfaces are historically believed to be a weak point in the physical barrier, as natural openings for pathogen entry. However, recent studies suggest that stomata can restrict pathogen entry as part of plant innate immunity (Melotto et al. 2008).

†Corresponding author: E. Johnson; egjohnson@ufl.edu

Funding: This work was supported by Scottish Crop Research Institute-Citrus Disease Research and Extension Foreign Agricultural Service award number 201570016-23030 and by the United States Department of Agriculture-National Institute of Food and Agriculture and Citrus Research and Development Foundation award number 545.

*The $e$-Xtra logo stands for "electronic extra" and indicates that supplementary materials are published online.

The author(s) declare no conflict of interest.

This article is in the public domain and not copyrightable. It may be freely reprinted with customary crediting of the source. The American Phytopathological Society, 2020. work, for the first time, creates a solid $P$. nicotianae zoospore infection protocol, reports $P$. nicotianae infection on citrus leaves through stomata, and provides evidence that different host organs respond to the pathogen differentially in timing and magnitude. This work identifies the hormones, sugars, pathogenesis-related genes, PLDs, and PLAs that are involved in the molecular events occurring in citrus under infection of $P$. nicotianae zoospore, and advances our understanding of the mechanisms underlying the interaction.

Keywords: citrus, defense genes, hormonal regulation, mycology, phospholipases, Phytophthora nicotianae, plant stress and abiotic disorders, stomata, sugar metabolism

Plant resistance genes, triggered by specific effectors of pathogens, activate a series of events leading to either pathogen inhibition or disease development. Biochemical and structural plant defense processes are regulated by cross-talk of signaling pathways, involving small molecules such as phytohormones, sugars, phospholipase D (PLD), phospholipase A (PLA), and so on. For example, stomatal closure upon exposure to bacteria is regulated by abscisic acid (ABA) signaling in guard cells through recognition of PAMPs (Melotto et al. 2008; Underwood et al. 2007), and PLD $\alpha$ was found to mediate this signaling pathway (Wang 2002). Phytophthora infestans virulence were found to be increased with activation of PLDs (Meijer et al. 2018). Classically, salicylic acid (SA)-mediated pathways act against biotrophic and hemibiotrophic pathogens by activating the expression of plant resistance genes, such as pathogenesis-related (PR) proteins PR1, PR2, and PR5. Jasmonic acid/ethylene (JA/ET)-mediated pathways act against necrotrophic pathogens and herbivorous insects (McConn et al. 1997; Pieterse et al. 2009). The antagonism between SA- and JA/ET-regulated pathways has been mostly documented in Arabidopsis thaliana (Glazebrook 2005), and proposed to be a plant strategy to prioritize the most effective defense in each case (Pieterse et al. 2009). However, recent studies showed that the interplay between these hormone-regulated signaling pathways varies from one disease to another (Attard et al. 2010; de Vries et al. 2018; Lemarié et al. 2015). Furthermore, sucrose, glucose, and fructose have been recognized as signaling molecules that prepare a plant for a more rapid and stronger defense against pathogen infection, which might interact with hormone pathways leading to an effective immune response (Bolouri Moghaddam and Van Den Ende 2012; Gómez-Ariza et al. 2007).

Although molecular plant-pathogen interaction has been extensively documented for the aerial parts of hosts, comparatively little is known about the mechanisms involved in root defense against soilborne pathogens (De Coninck et al. 2015). Studies investigating root responses to soilborne pathogens are often performed on leaves of the specific host or on leaves or roots of the model plant 
A. thaliana, assuming a similar response between differential hosts and organs (Attard et al. 2010; Boava et al. 2011a; De Coninck et al. 2015; Johansson et al. 2006). However, there is evidence that roots and leaves respond differently to infection by the same pathogen (Attard et al. 2010; Balmer et al. 2013; Hermanns et al. 2003; Le Fevre et al. 2016; Marcel et al. 2010). Previous studies used A. thaliana as a model plant because many genomic tools are available for manipulation (Attard et al. 2010; Roetschi et al. 2001). Transgenes from $A$. thaliana such as NPR1 have been utilized to enhance citrus resistance to pathogen infection (Dutt et al. 2015; Zhang et al. 2010). However, the study of model plants may not well represent every plant-pathogen interaction scenario (Schlaeppi et al. 2010). Findings for model plant leaves and roots may constrain our view of a specific plant-pathogen interaction, especially when extrapolating from a short-lived herbaceous plant to a perennial woody plant.

Phytophthora spp. cause several diseases of citrus worldwide, including damping-off of seedlings, root and crown rot in nurseries, and brown rot of fruit in orchards and postharvest fruit (Boava et al. 2011a,b; Graham and Feichtenberger 2015; Savita and Avinash 2012). Based on the citrus losses caused by Phytophthora diseases, knowledge of mechanisms underlying infection by Phytophthora spp. is of utmost importance for managing this pathogen (Boava et al. 2011a,b).

Limited information is currently available about the molecular interaction between citrus roots and Phytophthora spp., and the reported studies of citrus-Phytophthora spp. interactions were conducted on leaves and stems by mycelial plugs (Ajengui et al. 2018; Boava et al. 2011a,b). Zoospores of Phytophthora spp., which infect all parts of the citrus tree (Cacciola and Lio 2008), are more natural inoculum for evaluation of the differential plant defense response between leaves and roots, and to compare with findings from the model plant A. thaliana (Attard et al. 2010). P. nicotianae Breda de Haan (syn. P. parasitica) (Graham 1995; Kroon et al. 2012) is examined here because this Phytophthora sp. has been studied previously on citrus leaves and stems and on A. thaliana roots (Attard et al. 2010; Boava et al. 2011a,b). Furthermore, to study citrus leaves and roots response to $P$. nicotianae zoospore infection, an effective infection method needs to be examined as well.

In this study, we aimed to fill the gap by examining the mechanisms underlying the interaction of citrus roots and leaves with $P$. nicotianae. Roots and leaves were inoculated with zoospores to investigate differential defenses expressed by each plant tissue. We discussed hormone-regulated signaling pathways in roots with those described for A. thaliana roots (Attard et al. 2010), and compared the response in leaves with those described on citrus leaves after mycelial plug inoculation on stems (Boava et al. $2011 \mathrm{a}, \mathrm{b}$ ) to understand the effect of host and inoculation method on the interaction with $P$. nicotianae. We compared the physical characteristics and genetic responses to $P$. nicotianae infection in leaves and roots of susceptible and tolerant citrus rootstocks to examine the utility of leaves as an indicator for root response to $P$. nicotianae infection. This work identifies the genes for hormones, sugars, PRs, PLDs, and PLAs that are involved in the interaction of citrus and $P$. nicotianae, and provides evidence that different hosts and host organs respond to the pathogen differentially in timing and magnitude.

\section{MATERIALS AND METHODS}

Plant materials. Swingle citrumelo (Citrus paradisi $\times$ Poncirus trifoliata) (SC) and Cleopatra mandarin (C. reticulata) (CM) seed were sown in Metro Mix 500 (Hummert, International, Earth City, MO, U.S.A.) in $120-\mathrm{cm}^{3}$ containers $(3.8 \mathrm{~cm}$ in diameter and $21.0 \mathrm{~cm}$ in depth, SC10 cone-tainer; Steuwe \& Sons, Tangent, OR, U.S.A.) in the greenhouse. Seedlings were fertilized with $20 \mathrm{ml}$ of PETERS Pro 20-10-20 ( $\mathrm{N}$ concentration $=42 \mathrm{ppm})$
(Scotts-Sierra 84 Horticultural Products Company, Marysville, OH, U.S.A.) every other week and $6 \mathrm{~g}$ of Harrell's 18-5-10 (Harrell's, Lakeland, FL, U.S.A.) every 6 months, and watered three times per week. SC and CM seedlings of the same size (stem height $=50 \mathrm{~cm}$ ) were selected for leaf and root inoculation with Phytophthora nicotianae, and measurement of specific leaf area (SLA) and specific root length (SRL).

$P$. nicotianae maintenance and zoospore production. P. nicotianae isolate 198 was maintained on clarified V8 juice agar (Wu et al. 2018). Mycelium of P. nicotianae growing on clarified V8 juice agar was transferred to a Petri dish containing $0.25 \%$ water agar medium, and was incubated at room temperature in the dark for 4 to 5 days. Four growing edges of the P. nicotianae colony on water agar were transferred to Petri dishes of half concentrated V8 juice (V8/deionized [DI] water $=1: 9$ ), and incubated at room temperature in the dark for 7 days. The growing mycelium was washed three to four times in DI water to completely remove nutrients, covered by DI water, and incubated in light for 7 days for sporangia production. After observing the sporangia under a dissecting microscope, the culture was ready for evaluation of zoospore production and activity.

Two Petri dishes of $P$. nicotianae mycelium were mixed, and covered by $90 \mathrm{ml}$ of DI water in a 100-ml beaker. Mycelium was cold shocked at $4{ }^{\circ} \mathrm{C}$ for $30 \mathrm{~min}$ (Walker and van West 2007; Wang et al. 2013). Zoospore concentration in the solution was measured with a hemocytometer at 5, 15, 30, 60, and $120 \mathrm{~min}$ after removing the solution from the refrigerator. After analyzing zoospore production in the solution over time (Fig. 1A), 30 min was chosen for mycelium removal in further experiments. Another two Petri dishes of $P$. nicotianae mycelium were mixed in a $100-\mathrm{ml}$ beaker, kept at $4^{\circ} \mathrm{C}$ for $30 \mathrm{~min}$, and transferred to room temperature, and mycelium was removed after being kept for $30 \mathrm{~min}$ at room temperature. At $0,15,30,60$, and 120 min after removing the mycelium, zoospore concentration in the solution was measured with a hemocytometer (Fig. 1B). For routine zoospore production, mycelium was cold shocked at $4^{\circ} \mathrm{C}$ for $30 \mathrm{~min}$, placed at room temperature for another $30 \mathrm{~min}$, and removed from the solution. The resulting zoospore solution was used immediately after the mycelium was removed.

Detached leaf infection assays. CM healthy and fully expanded (mature) leaves were harvested from seedlings, and the leaf surface was cleaned by wiping with DI water. In all, 6 to 10 infection wounds (diameter $=1 \mathrm{~mm}$ ) between leaf blade and midribs were manually made at equidistant sites using a $1,000-\mu$ l pipette tip. A P. nicotianae zoospore solution was prepared and measured, and concentration ( 255 zoospores $/ \mu \mathrm{l})$ was recorded as described above. A $10-\mu l$ droplet of zoospore solution ( 255 zoospores/ $\mu \mathrm{l})$ was pipetted onto each wound for inoculation of CM leaves. Three additional wounded $\mathrm{CM}$ leaves were immersed in the same $P$. nicotianae zoospore solution for $20 \mathrm{~min}$, and three wounded $\mathrm{CM}$ leaves were immersed in DI water as controls. Zoospore concentrations were measured and recorded immediately after leaves were removed. A second set of three wounded CM leaves were immersed in the remaining zoospore solution or DI water for 20 min. The wounded CM leaves that were removed from the zoospore solution and DI water were immediately transferred to a Petri dish lined with one layer of filter paper (Whatman number 41). Each filter paper was soaked with $500 \mu \mathrm{l}$ of DI water to provide humidity. The plates were sealed with Parafilm and incubated in the dark at room temperature. To maintain humidity, $200 \mu \mathrm{l}$ of DI water was added to each plate every other day. At 5 days postinoculation (dpi), the leaves were evenly spread on the white background of an Epson 37 scanner (scale $=100 \%$, dots per inch $=1,200$, and Bit depth $=48$ ) to obtain digital color images (TIFF images) for each sample. To compare the susceptibility of SC and CM leaves to $P$. nicotianae infection, a solution of zoospores was prepared, and concentration was calculated at 200 zoospores/ $\mu 1$. Three wounded $\mathrm{SC}$ and $\mathrm{CM}$ leaves were immersed in the zoospore solution for 
20 min, and three wounded SC and CM leaves were immersed in DI water as controls. Inoculated SC and CM leaves were processed as described above. Digital color images were obtained at 5 dpi. After taking the digital image, the inoculated and noninoculated SC and
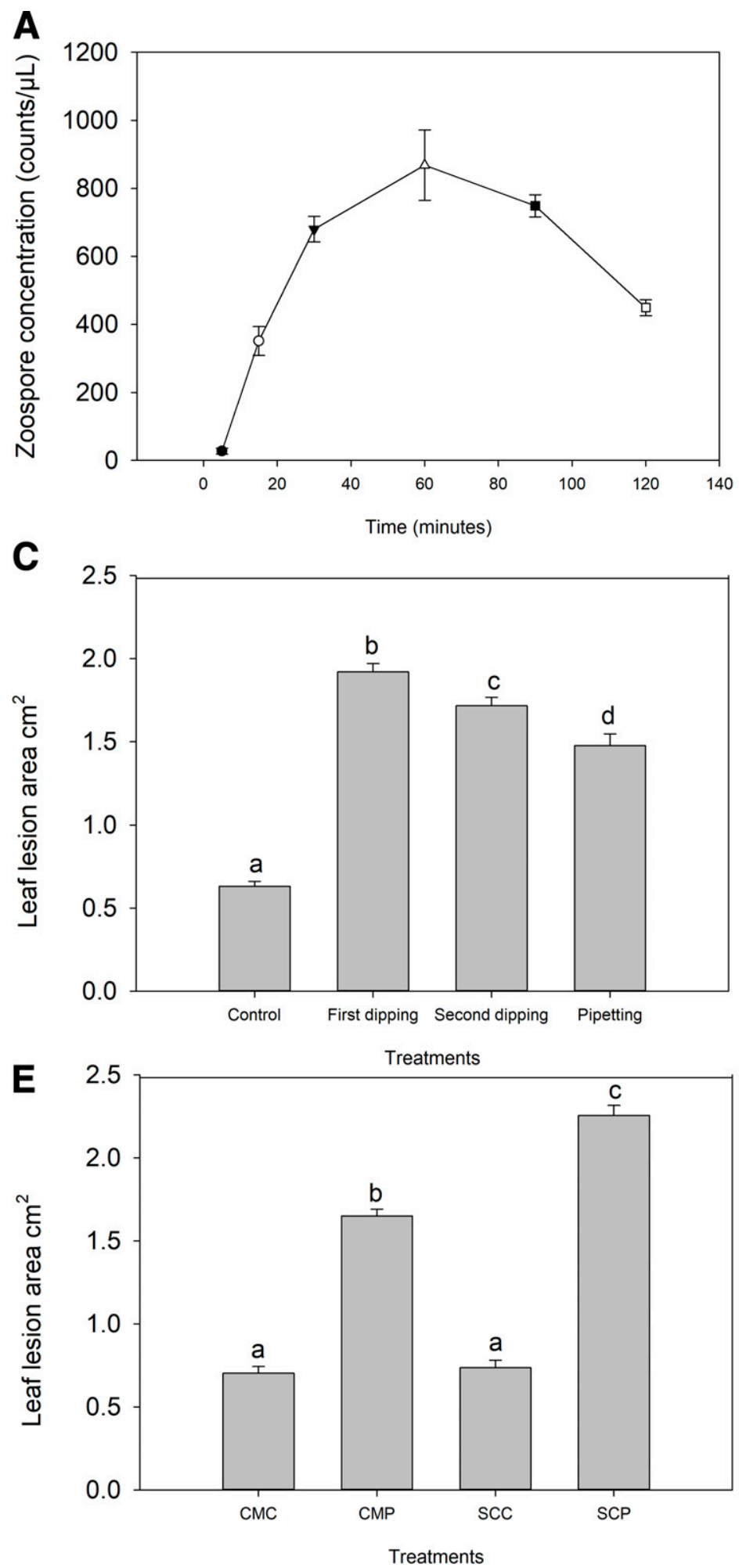

CM leaves were sealed in a Petri dish for a month, and pictures were taken to estimate the extent of lesion development. To measure lesion area, digital color images were analyzed with ImageJ software (Papadopulos et al. 2007).

B
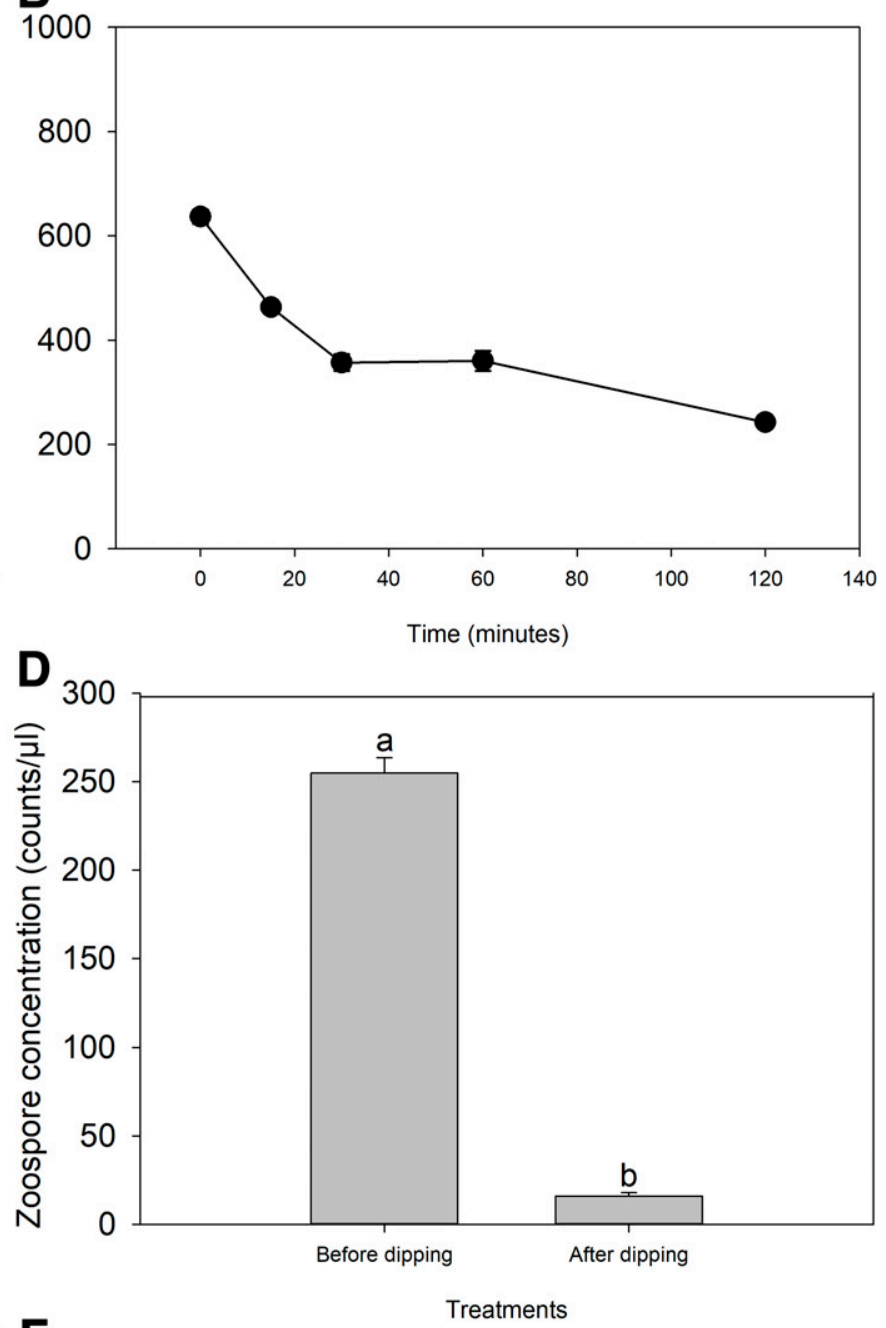

$\mathbf{F}$

\section{Cleopatra mandarin Swingle citrumelo}

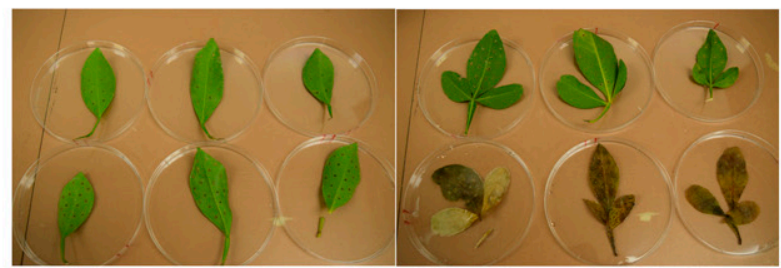

Fig. 1. Comparison response to Phytophthora nicotianae infection of Cleopatra mandarin (Citrus reticulata) $(\mathrm{CM})$ and Swingle citrumelo $(C$. paradisi $\times$ Poncirus trifoliata) (SC) detached fully expanded leaves. A, P. nicotianae zoospore release from sporangium at 5, 15, 30, 60, 90 , and 120 min after 30 min of cold shock. B, P. nicotianae zoospore concentration in solution over time after mycelium was removed (mycelium remained in solution for 30 min after the cold shock). C, Comparisons of the effect of differential inoculation methods on lesion development on CM detached expanded leaves. D, P. nicotianae zoospore concentration before and after dipping leaves in the solution. E, Comparison of lesion area developed on $\mathrm{CM}$ and $\mathrm{SC}$ detached leaves infected with $P$. nicotianae at 5 days postinoculation (dpi). CMC $=\mathrm{CM}$ control, $\mathrm{CMP}=\mathrm{CM}$ infected with $P$. nicotianae, $\mathrm{SCC}=\mathrm{SC}$ control, and SCP $=\mathrm{SC}$ infected with $P$. nicotianae. $\mathbf{F}$, Lesion development on $\mathrm{CM}$ and $\mathrm{SC}$ detached expanded leaves at 30 dpi. Upper row: controls without pathogen inoculation. Bottom row: $P$. nicotianae-infected detached leaves. Bars represent standard error. Different letters denote significant difference at $P \leq 0.05$ between each treatment. 
Attached leaf and root infection assays. $P$. nicotianae zoospores at 30 zoospores/ $\mu$ l were produced as described above. Three attached SC and CM expanding (immature) leaves were wiped clean using DI water and immersed in P. nicotianae zoospore solution for $2 \mathrm{~h}$. Three attached SC and CM leaves were immersed in DI water for $2 \mathrm{~h}$ as controls. Inoculated and noninoculated SC and CM seedlings were bagged to maintain $100 \%$ humidity, and kept at room temperature until sampling. One leaf from each plant was sampled at 4, 20, and $72 \mathrm{~h}$ postinoculation (hpi), put into 2-ml screwcap tubes with one 5-mm stainless steel bead (Qiagen, Valencia, CA, U.S.A.), and immediately frozen with liquid nitrogen. Samples were stored at $-80^{\circ} \mathrm{C}$ for RNA extraction. Symptomatic leaves were inserted into pimaricin-ampicillinrifampcin-pentachloronitrobenzene-hymexazol (PARPH) semiselective agar medium (Graham 1995). P. nicotianae hypha and sporangium growth was monitored. Similarly, expanded SC and $\mathrm{CM}$ attached leaves were inoculated as described above. However, no symptoms developed.

SC and CM seedlings planted in Metro Mix 500 were transferred into autoclaved Candler fine sand in $120-\mathrm{cm}^{3}$ containers for roots to adjust for 1 week. Containers were cut along the side before inoculation for easier sampling of roots after inoculation. Roots from three SC and CM seedlings were rinsed with DI water and immersed in a zoospore solution at 30 zoospores/ $\mu 1$. Three SC and $\mathrm{CM}$ seedlings roots were immersed in DI water as controls. After inoculation, roots were transferred into fresh autoclaved Candler fine sand at $15 \%$ soil moisture in the cut $120-\mathrm{cm}^{3}$ containers. The containers were sealed with tape and plastic bags, and laid horizontally. During harvest, cut containers were opened from the side, and $100 \mathrm{mg}$ of roots was randomly sampled without disturbing the rest of the root system at 4, 20, and 72 hpi and stored in liquid nitrogen immediately, as described above for leaf sampling. Containers were sealed after sampling and remained horizontal. These samples were stored at $-80^{\circ} \mathrm{C}$ for RNA extraction.

Scanning electron microscopy. Attached expanding and expanded SC and CM leaves were inoculated with $P$. nicotianae zoospores as described above. At 4 and $20 \mathrm{hpi}$, leaves were harvested and fixed in 4\% paraformaldehyde (Electron Microscopy Sciences, Hatfield, PA, U.S.A.) overnight. Samples were dehydrated in 30, 50, 70, 80, 90, and 100\% ethanol series for $1 \mathrm{~h}$ in each concentration and dried using a Ladd 28000 critical point dryer (Ladd Research Industries, Williston, VT, U.S.A.), and coated with palladium/gold using a Ladd 30800 sputter coater (Ladd Research Industries). P. nicotianae-inoculated and noninoculated SC and CM leaf samples were examined using a Hitachi S-4000 scanning electron microscope (Hitachi, Tokyo, Japan).

Gene expression analysis in leaves and roots. RNA extraction, cDNA synthesis, and quantitative reverse-transcription (qRT)-qPCR processes were performed as previously described (Wu et al. 2018). Briefly, RNA was extracted from roots of SC and CM using a RNeasy Mini kit (Qiagen). After the concentration was checked by ND-1000 spectrophotometer (NanoDrop Technologies, DE, U.S.A.), $1 \mu \mathrm{g}$ of total RNA was used for cDNA synthesis with a QuantiTect Reverse Transcription kit (Qiagen). qRT-PCR amplification was performed on a 7500 Fast Real-Time PCR System (Applied Biosystems) using a QuantiTect SYBR Green PCR kit

TABLE 1. Specific leaf area of Cleopatra mandarin (Citrus reticulata) and Swingle citrumelo (C. paradisi $\times$ Poncirus trifoliata) seedlings

\begin{tabular}{lcc}
\hline & \multicolumn{2}{c}{ Mean $\left(\mathrm{cm}^{2} / \mathrm{g}\right) \pm \mathrm{SE}^{\mathrm{z}}$} \\
\cline { 2 - 3 } Repeat & Cleopatra mandarin & Swingle citrumelo \\
\hline Repeat 1 & $124.6 \pm 6.2 \mathrm{a}$ & $159.9 \pm 3.6 \mathrm{~b}$ \\
Repeat 2 & $132.9 \pm 8.3 \mathrm{a}$ & $164.7 \pm 8.5 \mathrm{~b}$ \\
\hline z $\mathrm{SE}=$ standard error. Different letters denote significant difference at $P \leq 0.05$ \\
within each repeat.
\end{tabular}

(Qiagen). We studied genes that are involved in sucrose cleavage in the vacuole, sucrose cleavage and synthesis in the cytoplasm, SA biosynthesis pathways and downstream product proteins, ET biosynthesis pathways, ABA biosynthesis pathways, JA biosynthesis pathways, auxin biosynthesis pathways, five isoforms of PLD, and two isoforms of PLA. Sequences and references for the primer sets are listed in Supplementary Tables S1 and S2. Primers for genes involved in JA and auxin biosynthesis were designed based on the sequences for $A O C 3$ (JA biosynthesis pathways) and $A M I$ and $A A O$ (auxin biosynthesis pathways) by software Primer 3. The primer amplification efficiency was tested, relative gene expression was calculated by the $2^{-\Delta \Delta C t}$ method (Livak and Schmittgen 2001), and the result was expressed as $\log _{2}$-fold change. $18 S$ rRNA was used as the reference gene for the calculation.

SLA and SRL measurement. To measure SLA, 10 to 15 fully expanded SC and CM leaves were randomly selected, grouped, and scanned together to obtain digital color images (TIFF images, dots per inch $=600$ and Bit depth $=48$ ) as described above for the leaf lesion assay. To avoid the bias caused by differential leaf shapes and sizes, five groups of 10 to 15 leaves were scanned, and the total value of each scan was used for calculation of SLA. The whole step was repeated twice (Table 1). To measure SRL, soil of fibrous roots of 15 SC and CM seedlings was washed off for the first repeat, and 7 SC and $\mathrm{CM}$ seedlings were used for the second repetition. Fibrous roots were spread and scanned. After scanning, the leaves and roots were dried in an oven $\left(70^{\circ} \mathrm{C}\right)$ for $48 \mathrm{~h}$ and weighed. The images were analyzed by WinRHIZO Pro (Regent Instrument Inc., Québec, Canada) with color classes built according to the manufacturer's instructions (Wu et al. 2018). SLA and SRL were expressed as the total leaf area divided by total dry leaf weight and total roots length divided by total dry root weight, respectively.

Statistical analysis. Each experiment was performed at least twice, with three replicate plants per treatment. Data from gene expression analysis were highly similar between repetitions and, therefore, pooled for statistical analysis. P. nicotianae zoospore production and activity, leaf lesion area, gene expression data, SLA, and SRL were analyzed by one-way analysis of variance with least significant difference (LSD) as a posthoc test, using PROC GLM (SAS v. 9.4). The significance level was set at $P \leq 0.05$, and results of statistical tests were listed in Supplementary Files S1 and S2.

\section{RESULTS}

Examination of $P$. nicotianae zoospore production by time and the effect of inoculation method on lesion development on leaves. P. nicotianae sporangia started releasing zoospores within 5 min after removal (mar) from the refrigerator $\left(-4^{\circ} \mathrm{C}\right)$ to room temperature. Zoospore concentration in the solution increased from 27 zoospores/ $\mu \mathrm{l}$ at 5 mar to 868 zoospores/ $\mu$ lat 60 mar, and dropped slowly afterward (Fig. 1A). This indicates that the balance of $P$. nicotianae zoospore production and encystment was reached at 60 mar, and much zoospore activity was decreasing before this time point. We wanted to use the active zoospore. Considering that most zoospores were produced by 30 mar and were highly active because of recent emergence, 30 mar was chosen as the time to measure zoospore activity. After removing the mycelium, zoospore concentration dropped by $44 \%$ within 30 min (Fig. 1B). Hence, zoospore encystment occurred as early as 30 mar and continued thereafter.

To examine the effect of inoculation method on lesion development, 30 mar was chosen for mycelium removal. Control CM leaves dipped in water for $20 \mathrm{~min}$ did not develop lesions, and the hole area was calculated and used as the lesion area. The total lesion area of other treatments included the hole areas. Wounded CM leaves dipped in the zoospore solution for the first 20 min developed an average lesion area of $1.9 \pm 0.05$ (standard error) $\mathrm{cm}^{2}$ at $5 \mathrm{dpi}$, which was significantly greater than the controls. Lesion area on 
CM leaves dipped in the zoospore solution for 20 min following the first set of inoculations was $1.7 \pm 0.05 \mathrm{~cm}^{2}$, significantly lower than the first set (Fig. 1C). Lesion area on CM leaves with zoospore solution pipetted on the wounded leaf was significantly lower at 1.5 $\pm 0.07 \mathrm{~cm}^{2}$ compared with both sets using the dipping inoculation method (Fig. 1C). Before leaves were dipped in the zoospore solution, the zoospore concentration was 255 zoospores/ $\mu$ l. After leaves were removed after the first $20 \mathrm{~min}$, the zoospore concentration was reduced by $94 \%$ to 16 zoospores/ $\mu$ l (Fig. 1D). Considering that $44 \%$ of the zoospores encysted within $30 \mathrm{~min}$ without disturbance, dipping leaves in solution resulted in additional zoospore encystment, causing approximately $50 \%$ reduction in zoospore concentration. At 5 dpi, lesion area on SC leaves was $2.25 \pm 0.06 \mathrm{~cm}^{2}$, which was significantly larger than the $1.65 \pm 0.04 \mathrm{~cm}^{2}$ lesion area on CM leaves (Fig. 1E). At $30 \mathrm{dpi}$, lesions developed over the entire area of SC leaves, whereas lesions on $\mathrm{CM}$ leaves remained proximal to the wound site (Fig. 1F).

$P$. nicotianae zoospore infection on $\mathrm{SC}$ and $\mathrm{CM}$ expanding leaves. Bagging of $\mathrm{CM}$ and $\mathrm{SC}$ attached young leaves after inoculation with $P$. nicotianae provided $100 \%$ humidity with water observed inside on the surface of the bag. No lesion was observed on $\mathrm{CM}$ and $\mathrm{SC}$ noninoculated control leaves (Fig. 2A and B). Lesions
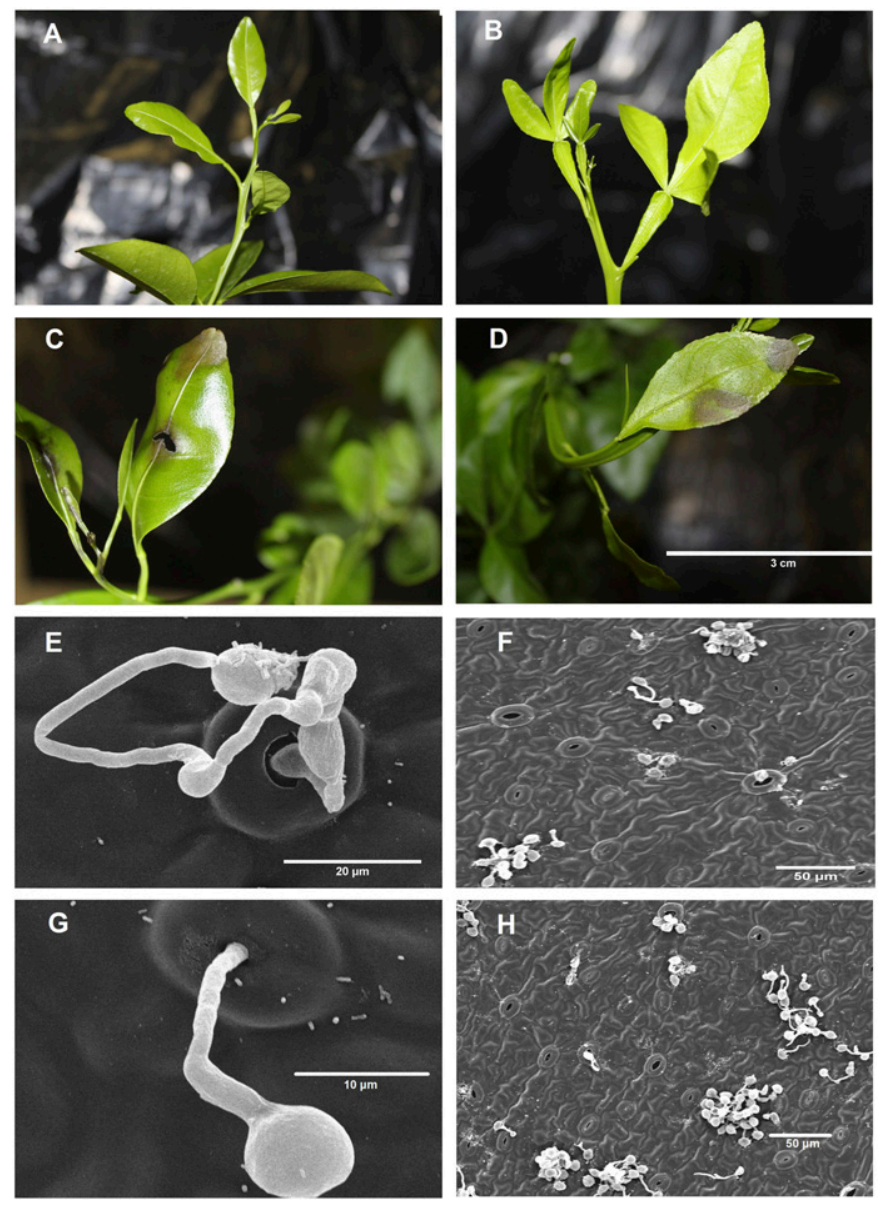

Fig. 2. Phytophthora nicotianae infection on Cleopatra mandarin (Citrus reticulata) $(\mathrm{CM})$ and Swingle citrumelo $(C$. paradisi $\times$ Poncirus trifoliata) (SC) attached expanding leaves. A, Expanding leaves of $\mathrm{CM}$ control seedlings. B, Expanding leaves of SC control seedlings. C, Disease symptom development on $\mathrm{CM}$ attached expanding leaves. D, Disease symptom development on $\mathrm{SC}$ attached expanding leaves. E, $P$. nicotianae penetration into $\mathrm{CM}$ attached expanding leaf through stomata. F, P. nicotianae penetration site on stomata of CM attached expanding leaf surface. G, $P$. nicotianae penetration into SC attached expanding leaf through stomata. H, P. nicotianae penetration site on stomata of CM attached expanding leaf surface. Bars $=3 \mathrm{~cm}(\mathrm{D}), 20 \mu \mathrm{m}(\mathrm{E})$, $50 \mu \mathrm{m}(\mathrm{F}), 10 \mu \mathrm{m}(\mathrm{G})$, and $50 \mu \mathrm{m}(\mathrm{H})$. developed on attached $\mathrm{CM}$ and $\mathrm{SC}$ expanding leaves at 1 to $2 \mathrm{dpi}$ (Fig. 2C and D), and leaves dropped at 2 or 3 dpi. Zoospores were mostly located in stomata of expanding CM (Fig. 2E and F) and SC leaves (Fig. 2G and H).

Comparisons of SLA and SRL of SC and CM. Comparing seedlings of each rootstock, CM had a significantly lower SLA than SC (Table 1). No difference was found in SRL of SC and CM (Table 2).

Relative expression of genes associated with SA, ET, ABA, JA, auxin biosynthesis, and plant PR genes in expanding leaves. We evaluated transcription of SA, ET, ABA, JA, auxin biosynthesis, and plant PR proteins through expression of key genes for each pathway. Genes monitored were $C M 1, C M 2$, $P A L$, and ICS for SA biosynthesis; $A C S 1, A C S 2$, and $A C O$ for ET biosynthesis; NCED for ABA biosynthesis; $A O C 3$ and $L O X$ for JA biosynthesis; $A M I$ and $A A O$ for auxin biosynthesis; and $P R 1, P R 2$, and PR5 for SA downstream protein products. In general, $P$. nicotianae induced similar gene expression in SC and CM. The expression of genes in $\mathrm{CM}$ and $\mathrm{SC}$ was altered as early as $4 \mathrm{hpi}$, and the change in expression continued in the same direction and at similar magnitude at $20 \mathrm{hpi}$. A few more genes started to show differential expression compared with controls at 20 hpi. In CM, most of the genes returned to control expression level by $72 \mathrm{hpi}$. In SC, $30 \%$ of the genes continued to have differential expression in the same direction and at similar magnitude, $20 \%$ of the genes that were upregulated at 4 hpi showed downregulation, and $50 \%$ of the genes returned to control expression levels by $72 \mathrm{hpi}$. At $4 \mathrm{hpi}$, the expression of genes associated with SA $(C M 1$, fold change $=11.84$, $P=0.0001)$, ET $(A C S 1$, fold change $=421.85, P<0.0001 ; A C S 2$, fold change $=109.51, P<0.001 ;$ and $A C O$, fold change $=23.37, P<$ $0.0001)$, and PR $(P R 2$, fold change $=2.44, P=0.08)$ were induced while genes associated with JA (AOC3, fold change $=-3.43, P=$ 0.015 ; and $L O X$, fold change $=-11.53, P=0.05)$ and auxin $(A M I$, fold change $=-5.75, P<0.0001$ ) were repressed by $P$. nicotianae The pattern and magnitude of differential expression was similar in $\mathrm{SC}$ and $\mathrm{CM}$ leaves. Induction of genes encoding PR ( $P R 1$, fold change $=3.7, P=0.09)$ and repression of $\mathrm{ABA}(N E C D$, fold change $=$ $-3.06, P=0.063$ ) encoding genes only occurred in SC at 4 hpi (Fig. 3). Differential expression of genes encoding SA (CM1, fold change $=5.09, P=0.002)$, ET $(A C S 1$, fold change $=2276.67, P<$ $0.0001 ; A C S 2$, fold change $=11.53, P=0.02$; and $A C O$, fold change $=$ $12.59, P=0.0004)$, and PR $(P R 2$, fold change $=12.11, P=0.0009)$ compared with controls continued upregulation in CM leaves at 20 hpi. Only genes encoding ET ( $A C S 1$, fold change $=1134.49, P<$ $0.0001)$ and PR $(P R 2$, fold change $=5.80, P=0.0018)$ were still upregulated at $20 \mathrm{hpi}$ in SC. At $20 \mathrm{hpi}$, expression of genes encoding SA (ICS) was downregulated in CM, and expression of genes encoding SA (ICS, fold change $=-27.04, P=0.0003)$ and PR $(P R 5$, fold change $=-30.98, P=0.006)$ was downregulated in SC (Fig. 3$)$. At 72 hpi, only expression of $P R 2$ (fold change $=4.37, P=0.01$ ) was upregulated in $P$. nicotianae-inoculated $\mathrm{CM}$ leaves compared with controls. In SC, the expression of $P R 2$ (fold change $=6.78, P=$ $0.0117)$ was upregulated, and genes encoding SA $(C M 1$, fold change $=-2.74, P=0.035 ;$ ICS 1 , fold change $=-6.34, P=0.02)$, ET $(A C S 2$, fold change $=-3.66, P=0.0633), \mathrm{JA}($ AOC 3 , fold change $=$ $-5.81, P=0.064)$, and auxin $(A M I$, fold change $=-3.13, P=0.064)$

TABLE 2. Specific root length of Cleopatra mandarin (Citrus reticulata) and Swingle citrumelo $(C$. paradisi $\times$ Poncirus trifoliata $)$ seedlings

\begin{tabular}{lcl}
\hline & \multicolumn{2}{c}{ Mean $\left(\mathrm{cm}^{2} / \mathrm{g}\right) \pm \mathrm{SE}^{\mathrm{z}}$} \\
\cline { 2 - 3 } Repeat & Cleopatra mandarin & Swingle citrumelo \\
\hline Repeat 1 & $1,330.7 \pm 62.7 \mathrm{a}$ & $1,318.3 \pm 42.3 \mathrm{a}$ \\
Repeat 2 & $1,412.5 \pm 84.7 \mathrm{a}$ & $1,299.5 \pm 192.1 \mathrm{a}$ \\
\hline
\end{tabular}

${ }^{\mathrm{z}} \mathrm{SE}=$ standard error. Different letters denote significant difference at $P \leq 0.05$ within each repeat. 
was downregulated by $P$. nicotianae in SC compared with controls (Fig. 3).

Relative expression of genes associated with sucrose metabolism, PLD, and PLA in expanding leaves. We followed the involvement of sucrose, PLD, and PLA by studying their associated genes' expression. Sucrose phosphate synthase (SPS) and AcidInv1, AcidInv2, CitCNV1, CitSuS1, and CitSuSA are involved in sucrose synthesis and cleavage. $P L D \alpha, P L D \beta, P L D \gamma$, $P L D \delta$, and $P L D \zeta$ are genes for five PLD isoforms with different functions. $P L A 2 \alpha$ and $P L A 2 \beta$ are genes for two PLA isoforms. $P$. nicotianae infection reduced expression of genes associated with sucrose synthesis $(S P S, \mathrm{CM}$ fold change $=-8.39, P<0.0001$; SC fold change $=-3.85, P=0.0266)$, PLDs $(P L D \alpha, C M$ fold change $=$ $-5.29, P=0.0016$, SC fold change $=-9.56, P=0.002 ; P L D \delta, \mathrm{CM}$ fold change $=-2.45, P=0.036$, SC fold change $=-2.58, P=0.026$ ), and PLA $(P L A 2 \alpha, \mathrm{CM}$ fold change $=-9.1, P=0.0083$; SC fold change $=-5.10, P=0.0134)$, and increased expression of sucrose cleavage (AcidInv1, CM fold change $=7.95, P=0.0006$; $\mathrm{SC}$ fold change $=12.13, P=0.0004 ;$ AcidInv $2, \mathrm{CM}$ fold change $=8.34, P=$ 0.0132 , SC fold change $=3.09, P=0.1 ;$ Cit $C N V 1$, fold change $=2.8$, $P=0.003$, SC fold change $=3.01, P=0.008)$ and PLDs $(P L D \gamma, \mathrm{CM}$ fold change $=13.39, P<0.0001, \mathrm{SC}$ fold change $=3.73, P=0.0009$; $P L D \zeta, \mathrm{CM}$ fold change $=2.60, P=0.02, \mathrm{SC}$ fold change $=4.21, P=$ 0.028 ) in expanding SC and CM leaves at 4 hpi compared with controls (Fig. 4). The effect of $P$. nicotianae on the expression of genes at $4 \mathrm{hpi}$, except $P L D \delta$, continued at $20 \mathrm{hpi}$ in the same direction and at similar magnitude in CM compared with the control (Fig. 4). P. nicotianae only affected the expression of genes encoding sucrose synthesis $(S P S$, fold change $=-5.17, P=0.1$ ), PLDs $(P L D \alpha$, fold change $=-11.17, P=0.005 ; P L D \gamma$, fold change $=$ $7.77, P=0.056)$, and PLA $(P L A 2 \alpha$, fold change $=-47.90, P=$ $0.0024)$ at $20 \mathrm{hpi}$ in expanding SC leaves compared with controls (Fig. 4). The expression of genes encoding sucrose cleavage (CitSuS1, fold change $=3.62, P=0.002$ ) was upregulated in $\mathrm{CM}$ at 20 hpi. The expression of genes encoding sucrose cleavage (CitSuSA, fold change $=-4.82, P=0.03$ ) was downregulated in
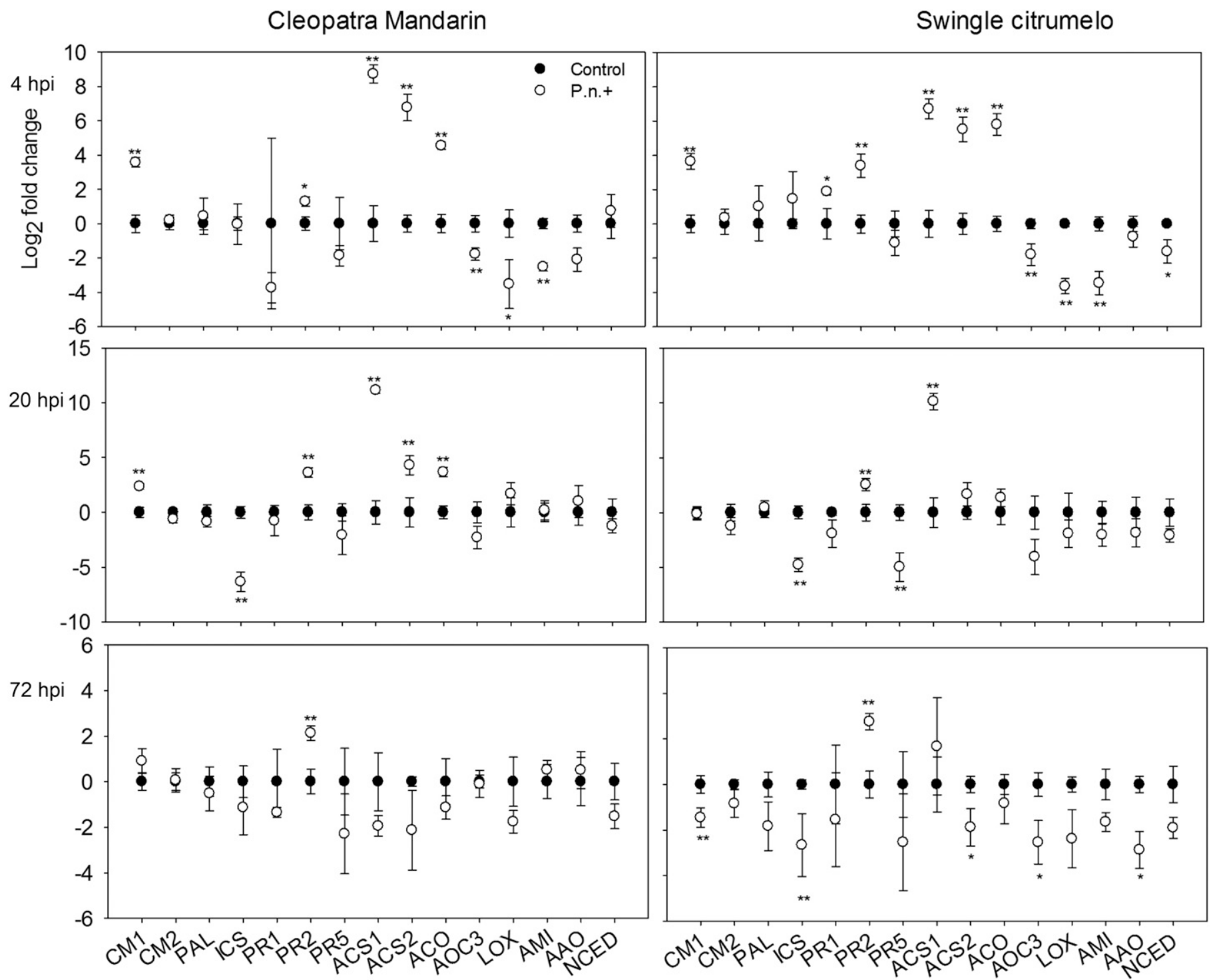

Fig. 3. Relative expression of genes associated with salicylic acid (SA), ethylene (ET), jasmonic acid (JA), auxin biosynthesis, and pathogenesis-related (PR) proteins PR1, PR2, and PR5 of Cleopatra mandarin (Citrus reticulata) $(\mathrm{CM})$ and Swingle citrumelo (C. paradisi $\times$ Poncirus trifoliata) $(\mathrm{SC})$ attached expanding leaves at 4,20 , and $72 \mathrm{~h}$ postinoculation (hpi) with Phytophthora nicotianae (P.n.), expressed as $\log _{2}$-fold change (calculated by the $2^{-} \Delta \Delta \mathrm{Ct}$ method). Genes monitored were CM1, CM2, PAL, and ICS for SA biosynthesis; ACS1, ACS2, and ACO for ET biosynthesis; NCED for abscisic acid biosynthesis; AOC3 and LOX for JA biosynthesis; $A M I$ and $A A O$ for auxin biosynthesis; and $P R 1, P R 2$, and $P R 5$ for SA downstream protein products. Bars represent standard error. Asterisks: ** denotes significant difference at $P \leq 0.05$ within each harvest and each rootstock and ${ }^{*}$ denotes significant difference at $0.05<P \leq 0.1$ within each harvest and each rootstock. 
SC at 20 hpi. At 72 hpi, only the expression of $P L D \gamma$ (fold change $=$ $3.39, P=0.07$ ) was slightly upregulated in CM compared with controls (Fig. 4). In P. nicotianae-infected SC expanding leaves, the expression of genes encoding sucrose cleavage (AcidInv2, fold change $=-3.97$, $P=0.001 ;$ CitSuSA, fold change $=-4.57, P=0.052)$ and PLDs $(P L D \gamma$, fold change $=-1.80, P=0.08 ; P L D \delta$, fold change $=-3.09, P=0.0002)$ was reduced compared with the control at 72 hpi (Fig. 4).

Relative expression of genes associated with SA, ET, ABA, JA, auxin biosynthesis, plant $P R$ proteins, sucrose metabolism, PLD, and PLA in roots. Gene expression responses were fewer and slower in $P$. nicotianae-infected roots compared with leaves. In general, more genes were activated in SC roots than CM roots at 4 and 20 hpi. At 4 hpi, P. nicotianae only increased the expression of genes encoding ET ( $A C S 2$, fold change $=6.22, P=0.0175)$ and reduced genes encoding sucrose cleavage (CitSuS1, fold change $=-3.24, P=0.0244$ ) in CM roots (Figs. 5 and 6 ). The expression of genes encoding ET ( ACS1, fold change $=6.03$, $P=0.008)$, PRs $(P R 1$, fold change $=3.58, P=0.1 ; P R 2$, fold change $=3.08, P=0.0728)$, and sucrose cleavage (AcidInv1, fold change $=$ $2.38, P=0.1$; AcidInv2, fold change $=4.79, P=0.0123$ ) was upregulated in SC roots compared with controls at 4 hpi (Figs. 5 and 6). In $P$. nicotianae-infected $\mathrm{CM}$ roots, the expression of genes encoding ET $(A C S 1$, fold change $=18.99, P=0.0045 ; A C O$, fold change $=11.58, P=0.0026)$ and PLDs $(P L D \gamma$, fold change $=4.15$, $P=0.012 ; P L D \zeta$, fold change $=3.75, P=0.0068)$ was increased, and gene encoding JA $(L O X$, fold change $=-8.62, P=0.0346)$ was
Cleopatra Mandarin
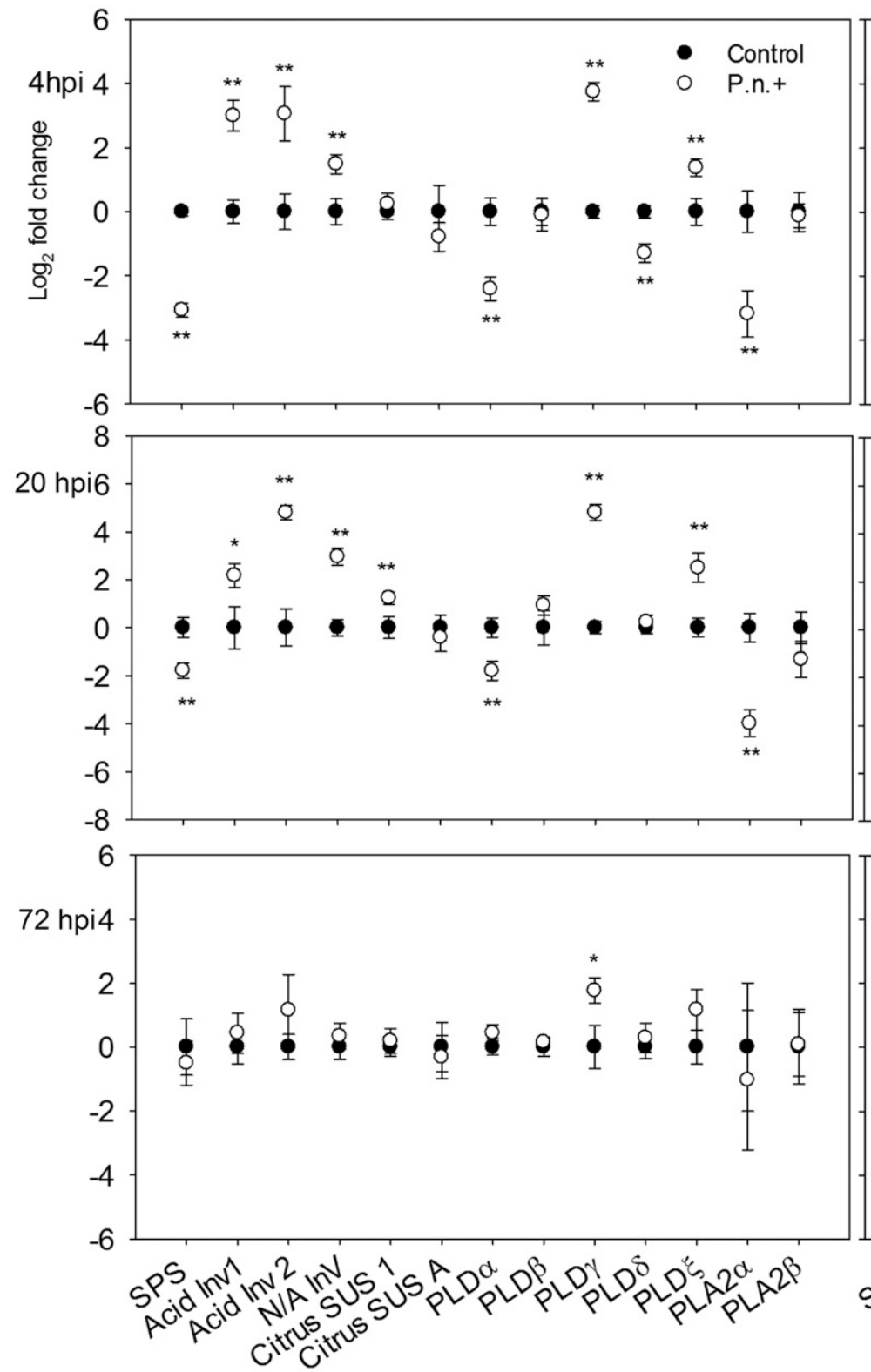

Swingle Citrumelo
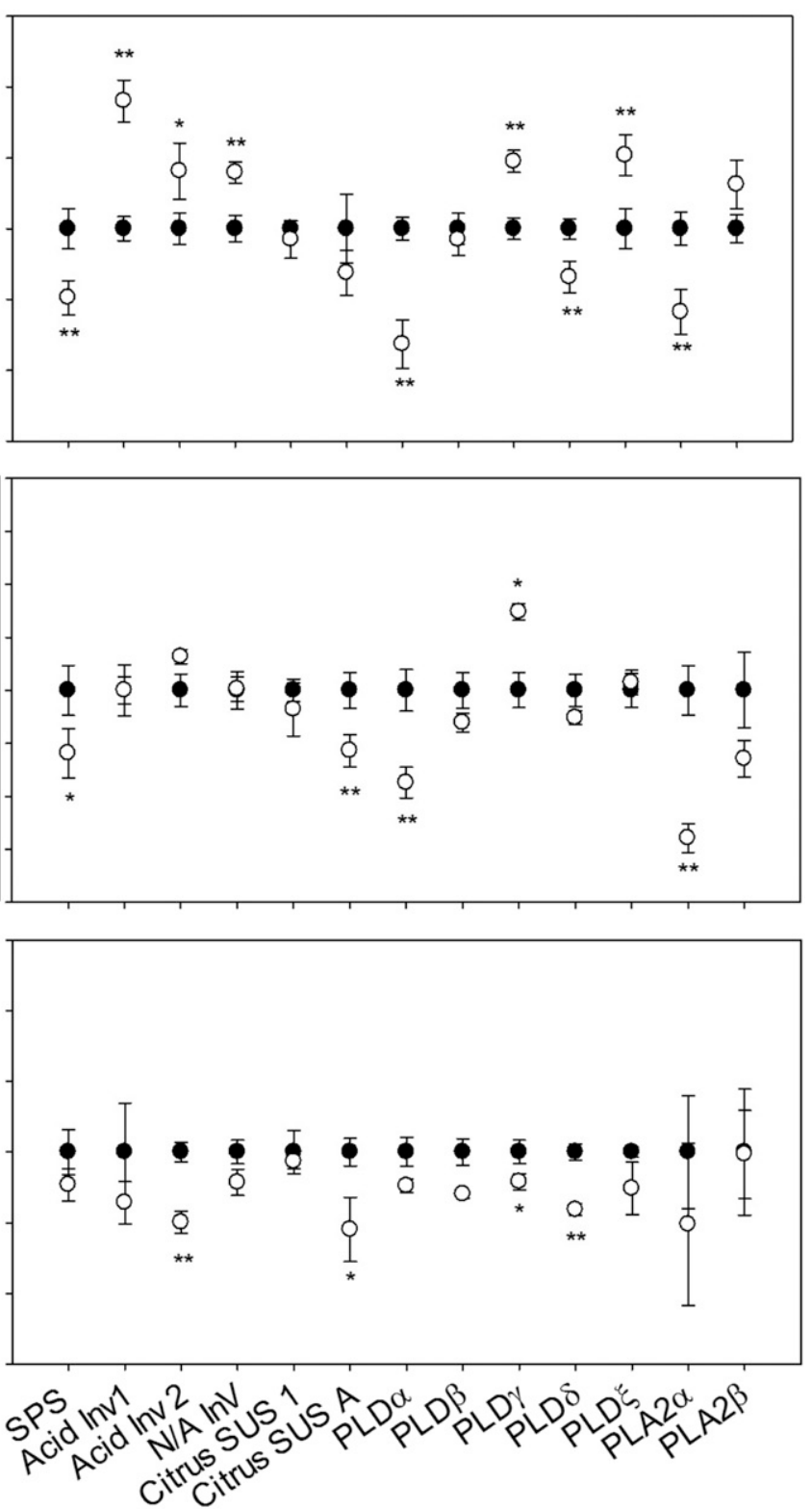

Fig. 4. Relative expression of genes associated with sucrose metabolism, phospholipase D (PLD), and phospholipase A (PLA) of Cleopatra mandarin (Citrus reticulata) $(\mathrm{CM})$ and Swingle citrumelo (C. paradisi $\times$ Poncirus trifoliata) $(\mathrm{SC})$ attached expanding leaves at 4,20 , and $72 \mathrm{~h}$ postinoculation (hpi) with Phytophthora nicotianae (P.n.), expressed as $\log _{2}$-fold change (calculated by the $2^{-\Delta \Delta \mathrm{Ct}}$ method). Genes monitored were sucrose phosphate synthase (SPS) for sucrose synthesis; AcidInv1, AcidInv2, CitCNV1, CitSuS1, and CitSuSA for sucrose cleavage; PLD $\alpha, P L D \beta, P L D \gamma, P L D \delta$, and PLD $\zeta$ for five PLD isoforms with different functions; and $P L A 2 \alpha$ and $P L A 2 \beta$ for two PLA isoforms. Bars represent standard error. Asterisks: ** denotes significant difference at $P \leq 0.05$ within each harvest and each rootstock and $*$ denotes significant difference at $0.05<P \leq 0.1$ within each harvest and each rootstock. 
reduced compared with controls at 20 hpi (Figs. 5 and 6). $P$. nicotianae increased the expression of genes encoding ET $(A C S 1$, fold change $=25.50, P=0.0004 ; A C O$, fold change $=13.60$, $P<0.0001)$, ABA (NCED, fold change $=7.33, P=0.0139)$, PLDs $(P L D \alpha$, fold change $=2.44, P=0.0072 ; P L D \beta$, fold change $=2.34$, $P=0.048 ; P L D \delta$, fold change $=2.97, P=0.0144 ; P L D \zeta$, fold change $=3.61, P=0.0031$ ), and sucrose cleavage (AcidInv1, fold change $=4.58, P=0.0009 ;$ AcidInv2, fold change $=17.57, P=$ 0.0003; CitCNV1, fold change $=3.09, P=0.0002)$ in SC compared with controls at $20 \mathrm{hpi}$. At $72 \mathrm{hpi}, P$. nicotianae increased the expression of genes encoding ET $(A C S 1$, fold change $=7.77, P=$ $0.05 ; A C O$, fold change $=4.73, P=0.063), \mathrm{PR}(P R 2$, fold change $=$ $5.75, P=0.018$ ), and sucrose cleavage (AcidInv2, fold change $=9.51$, $P=0.0236)$, and decreased the expression of genes encoding SA $(I C S$, fold change $=-2.56, P=0.0036)$ and $P R(P R 5$, fold change $=$ $-2.61, P=0.0786$ ) in CM roots compared with controls (Figs. 5 and 6). Upregulation of genes encoding ET (ACS2, fold change $=4.61$,
$P=0.0519 ; A C O$, fold change $=8.33, P=0.0629)$ and ABA $(N C E D$, fold change $=2.36, P=0.0184)$, and downregulation of genes encoding PLD $(P L D \delta$, fold change $=-2.26, P=0.06)$ and sucrose cleavage (CitSuSA, fold change $=-3.08, P=0.008$ ) were detected in $P$. nicotianae-infected SC roots compared with controls at $72 \mathrm{hpi}$ (Figs. 5 and 6).

\section{DISCUSSION}

Differences in the interaction between $P$. nicotianae and citrus leaves versus roots highlight the need to broaden our understanding of diverse pathogens with their specific hosts beyond that of the model plant $A$. thaliana, and the limitations of using leaf response to represent root response to pathogen infection.

Inoculation method affects lesion development. Thomson and Allen (1976) reported that P. nicotianae zoospores remained active up to $20 \mathrm{~h}$. Erwin and Ribeiro (1996) demonstrated that

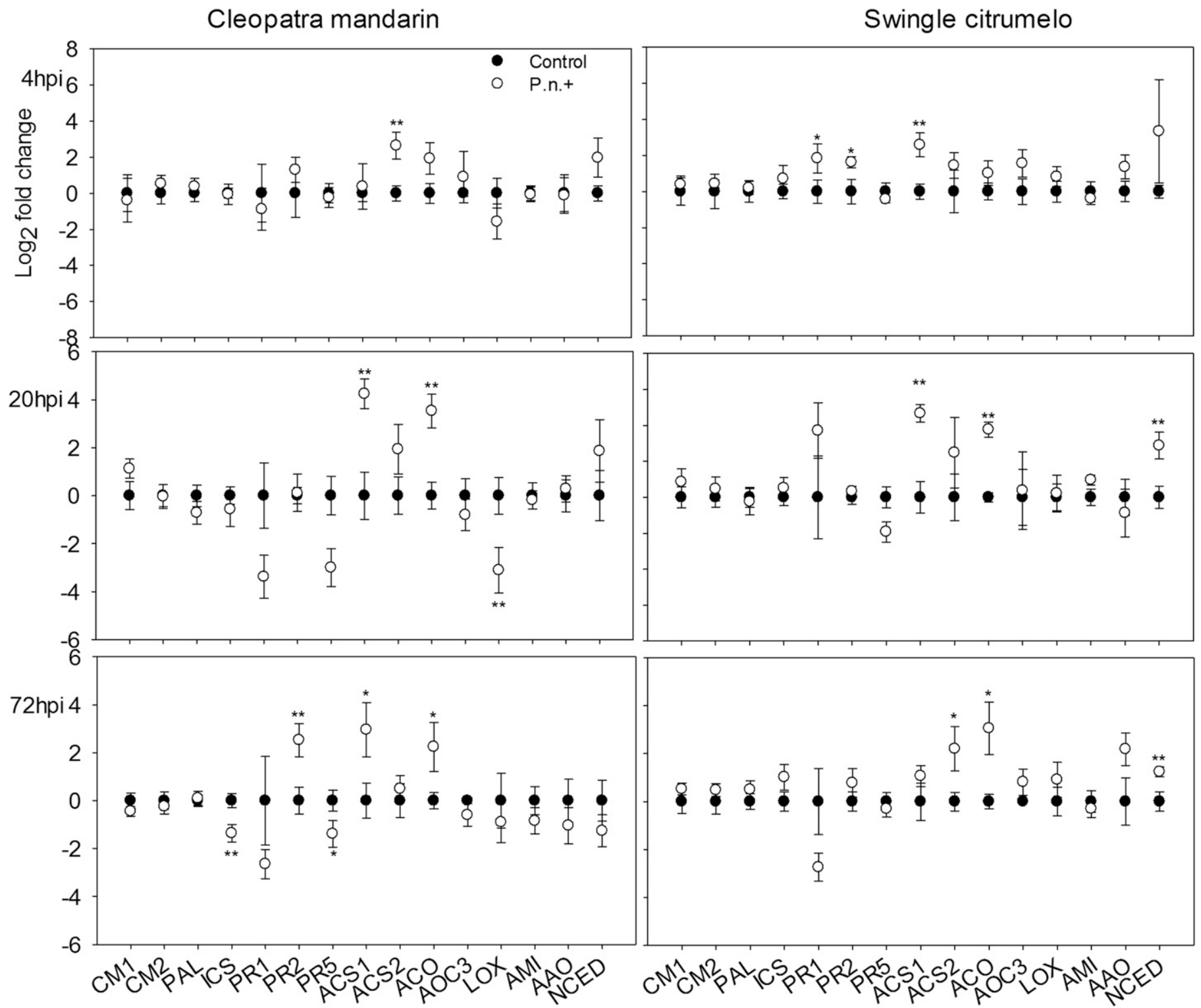

Fig. 5. Relative expression of genes associated with salicylic acid (SA), ethylene (ET), jasmonic acid (JA), auxin biosynthesis, and pathogenesis-related (PR) proteins PR1, PR2, and PR5 of Cleopatra mandarin (Citrus reticulata) $(\mathrm{CM})$ and Swingle citrumelo (C. paradisi $\times$ Poncirus trifoliata) $(\mathrm{SC})$ roots at 4,20 , and $72 \mathrm{~h}$ postinoculation (hpi) with Phytophthora nicotianae (P.n.), expressed as $\log _{2}$-fold change (calculated by the $2^{-\Delta \Delta C t}$ method). Genes monitored were $C M 1$, CM2, $P A L$, and ICS for SA biosynthesis; ACS1, ACS2, and ACO for ET biosynthesis; NCED for abscisic acid biosynthesis; $A O C 3$ and $L O X$ for JA biosynthesis; $A M I$ and $A A O$ for auxin biosynthesis; and $P R 1, P R 2$, and $P R 5$ for SA downstream protein products. Bars represent standard error. Asterisks: $* *$ denotes significant difference at $P \leq 0.05$ within each harvest and each rootstock and $*$ denotes significant difference at $0.05<P \leq 0.1$ within each harvest and each rootstock. 
contact with a solid surface and shaking greatly reduces zoospore activity. This implies that handling of $P$. nicotianae zoospores and time period of inoculation during the experiment creates variability, which could alter the effect of treatment. Therefore, it is important to select a reliable inoculation method to minimize this variability before investigating the interaction between $P$. nicotianae and citrus leaves and roots. In this study, monitoring of $P$. nicotianae zoospore release from sporangia over time showed that the rate of zoospore release and encystment reached an equilibrium at 60 mar, and that 30 mar is the optimum time point to remove mycelium from the solution in use of zoospores for inoculation. Dipping and pipetting are two common methods used for $P$. nicotianae zoospore inoculation that could cause zoospores to encyst. Probably, dipping increased the contact surface area for zoospores while pipetting created a disturbance similar to shaking. Hence, to obtain the most reliable inoculation, (i) $P$. nicotianae mycelium solution was kept in a refrigerator for $30 \mathrm{~min}$ and at room temperature for $30 \mathrm{~min}$ to maximize zoospore quality and quantity. Following that, mycelium was removed to create a more consistent zoospore concentration. (ii) Dipping could be used when screening a small number samples but the zoospore solution could only be used once. (iii) Pipetting disrupted zoospore activity in the remaining solution less severely compared with dipping. However, it took a longer time to place the zoospores on the inoculation site. Otherwise, the zoospores might have encysted significantly during the inoculation period. Testing each Phytophthora sp. and possibly even isolate to define the conditions for consistent zoospore inoculum preparation is essential to minimize variability.
Cleopatra mandarin
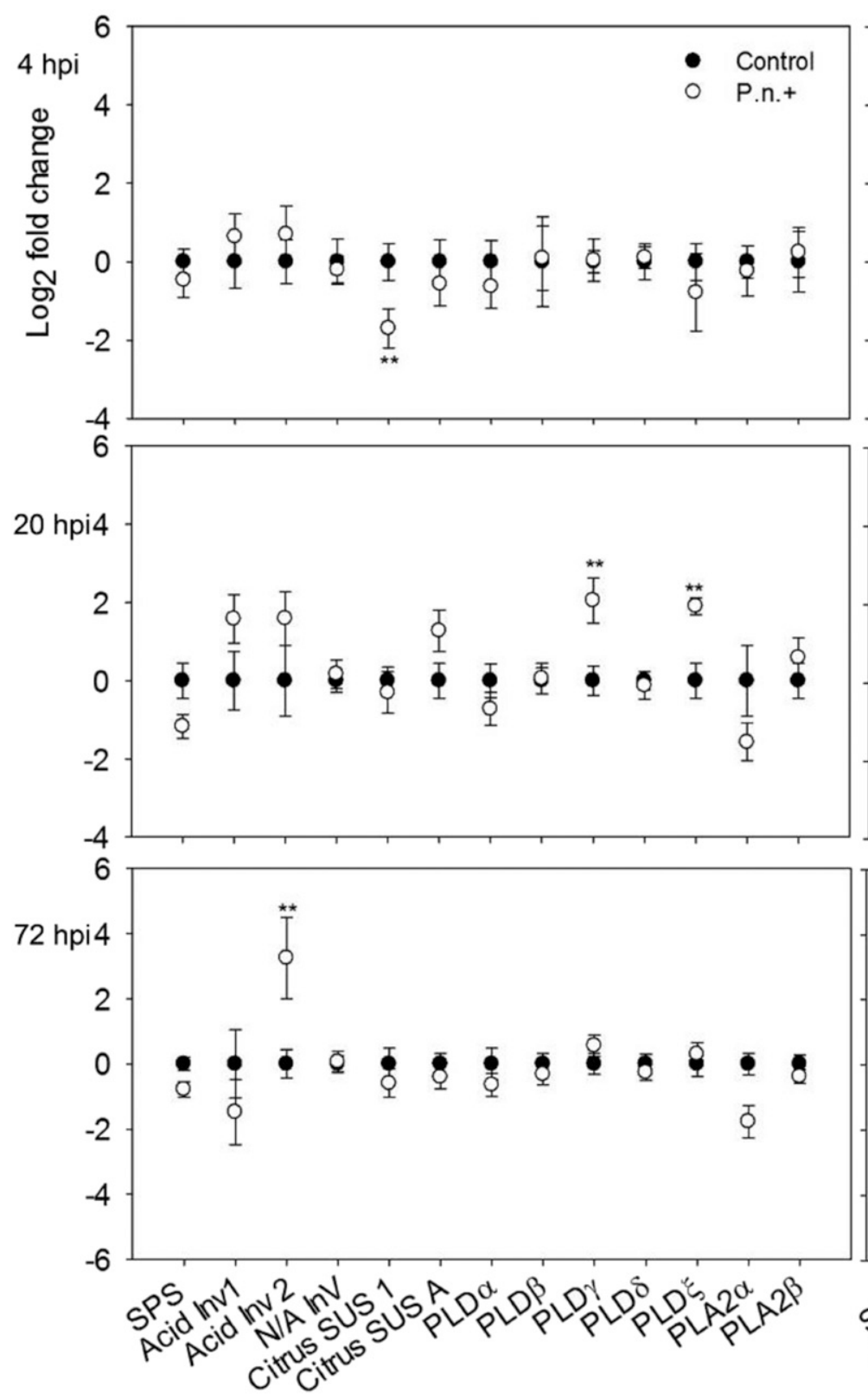

Swingle citrumelo
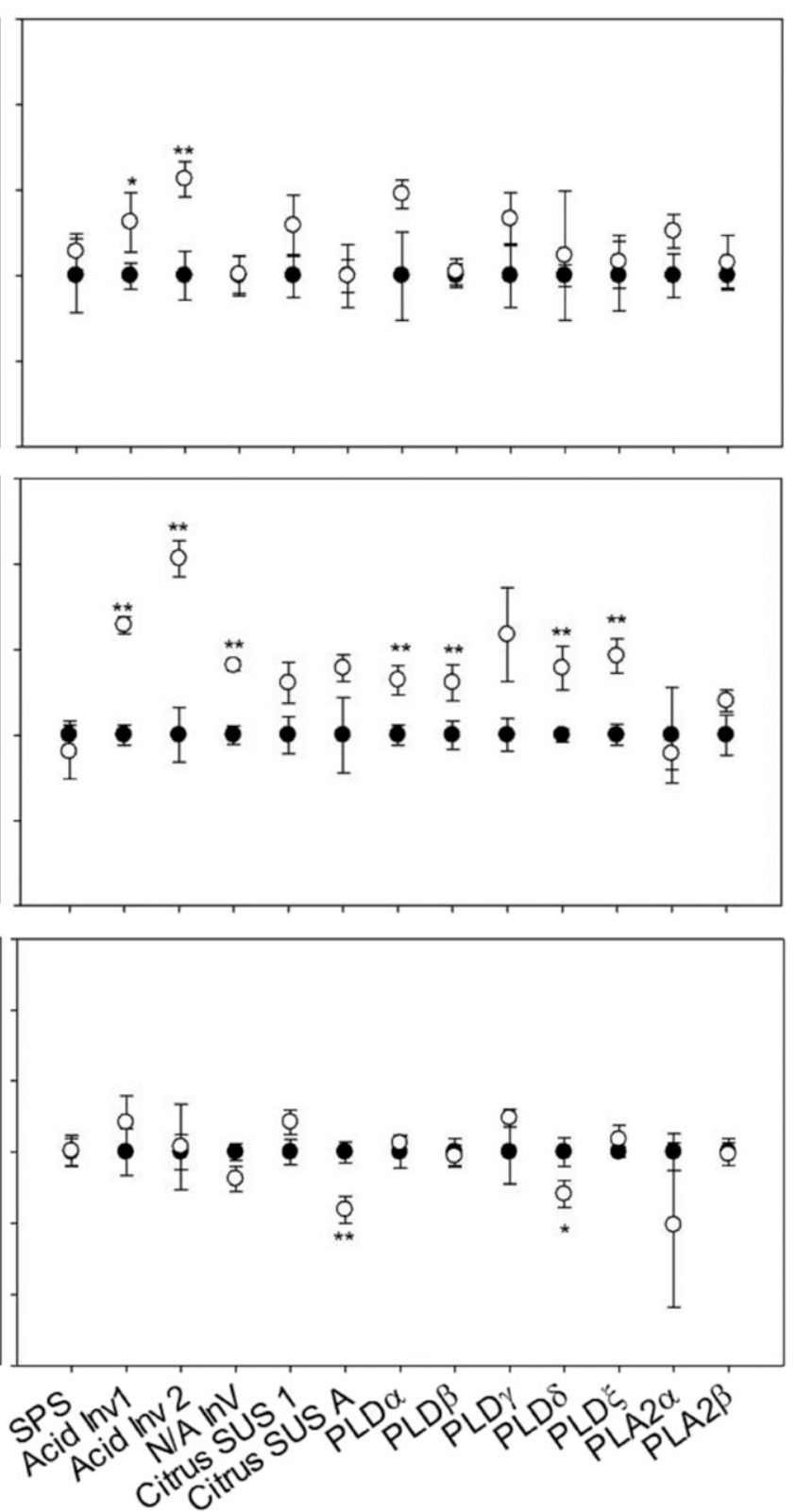

Fig. 6. Relative expression of genes associated with sucrose metabolism, phospholipase D (PLD), and phospholipase A (PLA) of Cleopatra mandarin (Citrus reticulata) $(\mathrm{CM})$ and Swingle citrumelo (C. paradisi $\times$ Poncirus trifoliata) $(\mathrm{SC})$ roots at 4,20 , and $72 \mathrm{~h}$ postinoculation (hpi) with Phytophthora nicotianae (P.n.), expressed as $\log _{2}$-fold change (calculated by the $2^{-\Delta \Delta C t}$ method). Genes monitored were sucrose phosphate synthase (SPS) for sucrose synthesis, AcidInv1, AcidInv2, CitCNV1, CitSuS1, and CitSuSA for sucrose cleavage; PLD $\alpha, P L D \beta, P L D \gamma, P L D \delta$, and $P L D \zeta$ for five PLD isoforms with different functions; and PLA2 $\alpha$ and $P L A 2 \beta$ for two PLA isoforms. Bars represent standard error. Asterisks: ** denotes significant difference at $P \leq 0.05$ within each harvest and each rootstock and * denotes significant difference at $0.05<P \leq 0.1$ within each harvest and each rootstock. 
Using the dipping method, both lesion development and gene expression analysis demonstrated that leaves and roots respond differently to $P$. nicotianae infection. $\mathrm{CM}$ and $\mathrm{SC}$ roots are susceptible and tolerant to $P$. nicotianae infection, respectively (Graham 1995). In contrast to root susceptibility, lesion area was significantly larger on SC leaves than CM. At the early stage of disease development, no significant difference in magnitude of the leaf gene expression response to $P$. nicotianae infection was found for CM compared with SC. With lower SLA, CM's thicker leaf structure may have provided a stronger physical barrier to $P$. nicotianae infection than SC.

Citrus respond to $P$. nicotianae infection differentially compared with Arabidopsis. Widmer et al. (1998) showed that $P$. nicotianae penetrated citrus fibrous roots at $1 \mathrm{hpi}$. The cortical cells adjacent to $P$. nicotianae hyphae were intact and disrupted at 24 and 48 hpi, respectively, which indicates a biotrophic followed by a necrotrophic phase (Attard et al. 2010). We checked the transcript events at 4, 20, and 72 hpi in the interaction between $P$. nicotianae and citrus roots by monitoring the expression of citrus homologs of Arabidopsis genes, and compared them with the interaction between P. nicotianae and Arabidopsis (Attard et al. 2010). Attard et al. (2010) reported that SA- and JA-dependent signaling pathways were both activated at the biotrophic phase but were downregulated during the switch to the necrotrophic phase, at which time ET-mediated signaling predominated. In our study, only ET-mediated signaling was activated in the interaction between $P$. nicotianae and citrus roots throughout the whole experiment. ABA was also involved in the interaction in addition to hormone signaling in SC. Our findings are consistent with previous reports that SA is not involved in the root-soil microbe interaction (Attard et al. 2010; Johansson et al. 2006). Furthermore, the downstream products of hormone signaling defense pathways (PR genes) were also differentially regulated in citrus roots compared with Arabidopsis. In Arabidopsis, PR1, PR2, and PR5 were found to be upregulated in roots. By contrast, $P R 1$ and $P R 2$ were slightly upregulated and $P R 5$ was downregulated in citrus roots at random sampling times, with no consistent responses between SC and CM. Due to technical limitations, the investigation of the citrus homologs of Arabidopsis genes provided us limited information, and more studies are needed to confirm the assumptions from current study.

Leaves and roots respond differentially to $P$. nicotianae infection. Comparison of the gene expression of roots and leaves to $P$. nicotianae infection showed that leaves respond to $P$. nicotianae infection faster and stronger than roots. Specifically, activation of the genes under evaluation started as early as 4 hpi in attached expanding leaves. Only some of the genes activated in leaves at $4 \mathrm{hpi}$ were altered in roots at 20 or $72 \mathrm{hpi}$. Furthermore, SA and ET responded to $P$. nicotianae infection at the same time in the leaves, whereas only ET was activated in the roots. The induction of defense-related marker genes upon pathogen infection in roots was often either less pronounced than in leaves or even completely lacking (Kidd et al. 2011; Marcel et al. 2010; Rookes et al. 2008). This might be related to the fact that many PR proteins are unevenly present in different organs (De Coninck et al. 2015; van Loon et al. 2006) and, accordingly, defense that depends on these proteins is differentially activated. By contrast with direct penetration of the epidermal cells in roots (Widmer et al. 1998), microscopy has shown that germ tubes of $P$. nicotianae zoospores infect young citrus leaves through stomata at $4 \mathrm{hpi}$ (Fig. 2E and F). The entry way might be the other reason that differential responses to $P$. nicotianae infection were activated in roots and leaves, because the different entry mechanisms might trigger different signaling pathways following penetration.

Sugars, especially sucrose and its cleavage products, play a role in plant development and the interaction between plant and pathogen by satisfying enhanced energy consumption or acting as signals to activate hormone-mediated defense pathways (Cho and
Yoo 2011; Gómez-Ariza et al. 2007; Koch 2004; Moore et al. 2003; Roitsch and González 2004; Tauzin and Giardina 2014). In the present study, we found that genes associated with sucrose cleavage and sucrose synthesis processes were upregulated and downregulated in the leaf response to $P$. nicotianae infection in both rootstocks. These findings suggest that, in leaves, sucrose might be cleaved to glucose and fructose to signal defense, or satisfy energy consumption for defense or pathogen utilization. In concert with less activation of plant defense-associated genes, only one sucrose cleavage gene (acid invertase 2 ) was found to be upregulated in roots of both rootstocks.

PLDs were also responsive in the interaction between $P$. nicotianae and citrus leaves and roots. PLDs break down phospholipids and produce a lipid phosphatidic acid (Canonne et al. 2011), which is a potent secondary signal messenger that might play a role in control of pathogen attack by activating ET-responsive genes (Testerink et al. 2008). Multiple PLDs have been described in plants with specific physiological functions under water stress conditions (Wang 2002). We identified gene expression of three PLD isoforms that were significantly altered in the interaction between $P$. nicotianae and leaves in both rootstocks. $P L D \gamma$ and $P L D \zeta$ were upregulated and $P L D \alpha$ was downregulated. Inhibition of PLD $\alpha$ activity was reported to impair stomatal closure induced by ABA and increase water loss from leaves (Austin-Brown and Chapman 2002; Sang et al. 2001). A repressor role of ABA on expression of $P L D \alpha$ was found in citrus fruit (Romero et al. 2014). In the present study, downregulation of $P L D \alpha$ was coincident with downregulation of $\mathrm{ABA}(N C E D)$ in $\mathrm{CM}$ and $\mathrm{SC}$ leaves. In contrast, $P L D \alpha$ and ABA (NCED) were upregulated in SC roots but not CM. This indicates that the interplay of PLD $\alpha$ and ABA is involved in the interaction in a similar way to that described for water stress in other studies (Wang 2002). Furthermore, PLD upregulated in CM leaves and $P L D \gamma, P L D \delta$, and $P L D \zeta$ were upregulated in SC leaves. This was in concert with upregulation of ET biosynthesis in leaves, indicating that these PLDs might be involved in the interaction by activating ET biosynthesis-responsive genes as previous study reported (Testerink et al. 2008). PLA degrades phospholipid to produce fatty acid, which is involved in production of JA (Canonne et al. 2011). PLA2 $\alpha$ was downregulated in leaves and roots of $\mathrm{CM}$; this is consistent with the downregulation of JA biosynthesis in both tissues. Similarly, PLA2 $\alpha$ was downregulated in SC leaves and barely altered in roots, which is in agreement with JA transcript events in each tissue. These results indicate that JA is not involved in the $P$. nicotianae-citrus interaction. Similarly, auxin is not involved in the interaction because its genes were either downregulated or not changed in leaves and roots of both rootstocks.

Host genotype and inoculation method might affect host-pathogen interaction. There is no citrus genotype truly resistant to $P$. nicotianae infection. Examination of pepper cultivars infected with $P$. capsici showed that regulation of defense-related genes is stronger and faster in a resistant genotype (Silvar et al. 2008). Boava et al. (2011b) and Ajengui et al. (2018) reported that similar genes were upregulated in both tolerant and susceptible citrus rootstocks to $P$. nicotianae infection, with higher magnitude change in the tolerant rootstock. In this study, there are more defense-related genes activated in SC roots than in CM. For example, upregulation of $P R 1$ and $P R 2$ in SC roots but not in CM roots at 4 hpi might help prevent disease development in $\mathrm{SC}$ roots at an early stage of infection. In the present study, similar SRL indicated comparable root physical structure between SC and CM. Thus, the tolerance of SC compared with $\mathrm{CM}$ roots might result from the products of differentially regulated genes.

Furthermore, plants might respond differently to the same pathogen under different inoculation methods. Boava et al. (2011b) reported that $P R 1, P R 2, P R 5, P A L$ (SA biosynthesis), and $L O X$ (JA biosynthesis) were upregulated in both tolerant and susceptible rootstocks' leaves with $P$. nicotianae infection of 
stems. However, we only found upregulation of $P R 2$ and $C M 1$ (SA biosynthesis) in both CM and SC leaves inoculated with zoospores.

Taken together, there are some similarities as well as differences between defense mechanisms employed by above- and belowground plant parts, and between model plant Arabidopsis and citrus. For the first time, we report $P$. nicotianae infection on citrus leaves through stomata after zoospore inoculation. P. nicotianae zoospores use differential strategies to enter roots and leaves, which may partially explain why roots and leaves respond to $P$. nicotianae infection differently at the molecular level. Finally, for the first time, we identified that sugar, PLDs, and PLA2s are involved in the interaction between citrus and $P$. nicotianae.

\section{ACKNOWLEDGMENTS}

We thank D. Bright, T. McIntosh, D. Stanton, and H. Chen for their technical assistance.

\section{LITERATURE CITED}

Ajengui, A., Bertolini, E., Ligorio, A., Chebil, S., Ippolito, A., and Sanzani, S. M. 2018. Comparative transcriptome analysis of two citrus germplasms with contrasting susceptibility to Phytophthora nicotianae provides new insights into tolerance mechanisms. Plant Cell Rep. 37:483-499.

Aragón, W., Reina-Pinto, J. J., Serrano, M., and Dominguez, E. 2017. The intimate talk between plants and microorganisms at the leaf surface. J. Exp. Bot. 68:5339-5350.

Attard, A., Gourgues, M., Callemeyn-Torre, N., and Keller, H. 2010. The immediate activation of defense responses in Arabidopsis roots is not sufficient to prevent Phytophthora parasitica infection. New Phytol. 187: 449-460.

Austin-Brown, S. L., and Chapman, K. D. 2002. Inhibition of phospholipase D alpha by N-acylethanolamines. Plant Physiol. 129:1892-1898.

Balmer, D., De Papajewski, D. V., Planchamp, C., Glauser, G., and Mauch-Mani, B. 2013. Induced resistance in maize is based on organspecific defence responses. Plant J. 74:213-225.

Boava, L. P., Cristofani-Yaly, M., Mafra, V. S., Kubo, K., Kishi, L. T., Takita, M. A., Ribeiro-Alves, M., and Machado, M. A. 2011a. Global gene expression of Poncirus trifoliata, Citrus sunki and their hybrids under infection of Phytophthora parasitica. BMC Genomics 12:39.

Boava, L. P., Cristofani-Yaly, M., Stuart, R. M., and Machado, M. A. 2011b. Expression of defense-related genes in response to mechanical wounding and Phytophthora parasitica infection in Poncirus trifoliata and Citrus sunki. Physiol. Mol. Plant Pathol. 76:119-125.

Bolouri Moghaddam, M. R., and Van Den Ende, W. 2012. Sugars and plant innate immunity. J. Exp. Bot. 63:3989-3998.

Cacciola, S. O., and Lio, G. M. D. S. 2008. Management of citrus diseases caused by Phytophthora spp. Pages 61-84 in: Integrated Management of Diseases Caused by Fungi, Phytoplasma and Bacteria. Integrated Management of Plant Pests and Diseases, vol. 3. A. Ciancio and K. Mukerji, eds. Springer, Dordrecht, The Netherlands.

Canonne, J., Froidure-Nicolas, S., and Rivas, S. 2011. Phospholipases in action during plant defense signaling. Plant Signal. Behav. 6:13-18.

Cho, Y. H., and Yoo, S. D. 2011. Signaling role of fructose mediated by FINS1/FBP in Arabidopsis thaliana. PLoS Genet. 7:e1001263.

Choi, H. W., and Klessig, D. F. 2016. DAMPs, MAMPs, and NAMPs in plant innate immunity. BMC Plant Biol. 16:232.

De Coninck, B., Timmermans, P., Vos, C., Cammue, B. P. A., and Kazan, K. 2015. What lies beneath: Belowground defense strategies in plants. Trends Plant Sci. 20:91-101.

de Vries, S., de Vries, J., von Dahlen, J. K., Gould, S. B., Archibald, J. M., Rose, L. E., and Slamovits, C. H. 2018. On plant defense signaling networks and early land plant evolution. Commun. Integr. Biol. 11:1-14.

Dodds, P. N., and Rathjen, J. P. 2010. Plant immunity: Towards an integrated view of plant-pathogen interactions. Nat. Rev. Genet. 11:539-548.

Dutt, M., Barthe, G., Irey, M., and Grosser, J. 2015. Transgenic citrus expressing an Arabidopsis NPR1 gene exhibit enhanced resistance against Huanglongbing (HLB; Citrus greening). PLoS One 10:e0147657.

Erwin, D. C., and Ribeiro, O. K. 1996. Phytophthora Diseases Worldwide. American Phytopathological Society Press, St. Paul, MN, U.S.A.

Glazebrook, J. 2005. Contrasting mechanisms of defense against biotrophic and necrotrophic pathogens. Annu. Rev. Phytopathol. 43:205-227.

Gómez-Ariza, J., Campo, S., Rufat, M., Estopà, M., Messeguer, J., San Segundo, B., and Coca, M. 2007. Sucrose-mediated priming of plant defense responses and broad-spectrum disease resistance by overexpression of the maize pathogenesis-related PRms protein in rice plants. Mol. PlantMicrobe Interact. 20:832-842.

Graham, J. 1995. Root regeneration and tolerance of citrus rootstocks to root rot caused by Phytophthora nicotianae. Phytopathology 85:111-117.

Graham, J., and Feichtenberger, E. 2015. Citrus phytophthora diseases: Management challenges and successes. J. Citrus Pathol. 2:1-11.

Hermanns, M., Slusarenko, A. J., and Schlaich, N. L. 2003. Organ-specificity in a plant disease is determined independently of $R$ gene signaling. Mol. Plant-Microbe Interact. 16:752-759.

Johansson, A., Staal, J., and Dixelius, C. 2006. Early responses in the Arabidopsis-Verticillium longisporum pathosystem are dependent on NDR1, JAand ET-associated signals via cytosolic NPR1 and RFO1. Mol. PlantMicrobe Interact. 19:958-969.

Ju, S., Go, Y. S., Choi, H. J., Park, J. M., and Suh, M. C. 2017. DEWAX Transcription Factor Is involved in resistance to Botrytis cinerea in Arabidopsis thaliana and Camelina sativa. Front. Plant Sci. 8:1210.

Kidd, B. N., Kadoo, N. Y., Dombrecht, B., Tekeoğlu, M., Gardiner, D. M., Thatcher, L. F., Aitken, E. A. B., Schenk, P. M., Manners, J. M., and Kazan, K. 2011. Auxin signaling and transport promote susceptibility to the rootinfecting fungal pathogen Fusarium oxysporum in Arabidopsis. Mol. PlantMicrobe Interact. 24:733-748.

Koch, K. 2004. Sucrose metabolism: Regulatory mechanisms and pivotal roles in sugar sensing and plant development. Curr. Opin. Plant Biol. 7: 235-246.

Kroon, L. P. N. M., Brouwer, H., de Cock, A. M., and Govers, F. 2012. The Genus Phytophthora Anno 2012. Phytopathology 102:348-364.

Le Fevre, R., O’Boyle, B., Moscou, M. J., and Schornack, S. 2016. Colonization of barley by the broad-host hemibiotrophic pathogen Phytophthora palmivora uncovers a leaf development dependent involvement of MLO. Mol. Plant-Microbe Interact. 29:385-395.

Lemarié, S., Robert-Seilaniantz, A., Lariagon, C., Lemoine, J., Marnet, N., Jubault, M., Manzanares-Dauleux, M. J., and Gravot, A. 2015. Both the Jasmonic acid and the Salicylic acid pathways contribute to resistance to the biotrophic clubroot agent Plasmodiophora brassicae in Arabidopsis. Plant Cell Physiol. 56:2158-2168.

Livak, K. J., and Schmittgen, T. D. 2001. Analysis of relative gene expression data using real-time quantitative PCR and the $2^{-\Delta \Delta C T}$ method. Methods 25 : 402-408.

Marcel, S., Sawers, R., Oakeley, E., Angliker, H., and Paszkowski, U. 2010. Tissue-adapted invasion strategies of the rice blast fungus Magnaporthe oryzae. Plant Cell 22:3177-3187.

McConn, M., Creelman, R. A., Bell, E., Mullet, J. E., and Browse, J. 1997. Jasmonate is essential for insect defense in Arabidopsis. Proc. Natl. Acad. Sci. U.S.A. 94:5473-5477.

Meijer, H. J. G., Schoina, C., Wang, S., Bouwmeester, K., Hua, C., and Govers, F. 2018. Phytophthora infestans small phospholipase D-like proteins elicit plant cell death and promote virulence. Mol. Plant Pathol. 20: 180-193.

Melotto, M., Underwood, W., and He, S. Y. 2008. Role of stomata in plant innate immunity and foliar bacterial diseases. Annu. Rev. Phytopathol. 46: 101-122.

Moore, B., Zhou, L., Rolland, F., Hall, Q., Cheng, W. H., Liu, Y. X., Hwang, I., Jones, T., and Sheen, J. 2003. Role of the Arabidopsis glucose sensor HXK1 in nutrient, light, and hormonal signaling. Science 300:332-336.

Nishimura, M. T., Stein, M., Hou, B. H., Vogel, J. P., Edwards, H., and Somerville, S. C. 2003. Loss of a callose synthase results in salicylic aciddependent disease resistance. Science 301:969-972.

Papadopulos, F., Spinelli, M., Valente, S., Foroni, L., Orrico, C., Alviano, F., and Pasquinelli, G. 2007. Common tasks in microscopic and ultrastructural image analysis using ImageJ. Ultrastruct. Pathol. 31:401-407.

Pieterse, C. M. J., Leon-Reyes, A., Van Der Ent, S., and Van Wees, S. C. M. 2009. Networking by small-molecule hormones in plant immunity. Nat. Chem. Biol. 5:308-316.

Ranathunge, K., Thomas, R. H., Fang, X., Peterson, C. A., Gijzen, M., and Bernards, M. A. 2008. Soybean root suberin and partial resistance to root rot caused by Phytophthora sojae. Phytopathology 98:1179-1189.

Reina-Pinto, J. J., and Yephremov, A. 2009. Surface lipids and plant defenses. Plant Physiol. Biochem. 47:540-549.

Roetschi, A., Si-Ammour, A., Belbahri, L., Mauch, F., and Mauch-Mani, B. 2001. Characterization of an Arabidopsis-Phytophthora pathosystem: Resistance requires a functional pad 2 gene and is independent of salicylic acid, ethylene and jasmonic acid signalling. Plant J. 28:293-305.

Roitsch, T., and González, M. C. 2004. Function and regulation of plant invertases: Sweet sensations. Trends Plant Sci. 9:606-613.

Romero, P., Lafuente, M. C. and Alférez, F. 2014. A transcriptional approach to unravel the connection between phospholipases A2 and D and ABA signal in citrus under water stress. Plant Physiol. Biochem. 80:23-32.

Rookes, J. E., Wright, M. L., and Cahill, D. M. 2008. Elucidation of defence responses and signalling pathways induced in Arabidopsis thaliana 
following challenge with Phytophthora cinnamomi. Physiol. Mol. Plant Pathol. 72:151-161.

Sang, Y., Zheng, S., Li, W., Huang, B., and Wang, X. 2001. Regulation of plant water loss by manipulating the expression of phospholipase D $\alpha$. Plant J. 28 : 135-144.

Savita, G. S. V., and Avinash, N. 2012. Citrus diseases caused by Phytophthora species. GERF Bull. Biosci. 3:18-27.

Schlaeppi, K., Abou-Mansour, E., Buchala, A., and Mauch, F. 2010. Disease resistance of Arabidopsis to Phytophthora brassicae is established by the sequential action of indole glucosinolates and camalexin. Plant J. 62: 840-851.

Silvar, C., Merino, F., and Diaz, J. 2008. Differential activation of defenserelated genes in susceptible and resistant pepper cultivars infected with Phytophthora capsici. J. Plant Physiol. 165:1120-1124.

Tauzin, A. S., and Giardina, T. 2014. Sucrose and invertases, a part of the plant defense response to the biotic stresses. Front. Plant Sci. 5:293.

Testerink, C., Larsen, P. B., McLoughlin, F., van der Does, D., van Himbergen, J. A., and Munnik, T. 2008. PA, a stress-induced short cut to switch-on ethylene signalling by switching-off CTR1? Plant Signal. Behav. 3: 681-683.

Thomson, S. V., and Allen, R. M. 1976. Mechanisms of survival of zoospores of Phytophthora parasitica in irrigation water. Phytopathology 66:1198-1202.

Underwood, W., Melotto, M., and He, S. Y. 2007. Role of plant stomata in bacterial invasion. Cell. Microbiol. 9:1621-1629. van Loon, L. C., Rep, M., and Pieterse, C. M. J. 2006. Significance of inducible defense-related proteins in infected plants. Annu. Rev. Phytopathol. 44:135-162.

Walker, C. A., and van West, P. 2007. Zoospore development in the oomycetes. Fungal Biol. Rev. 21:10-18.

Wang, X. 2002. Phospholipase D in hormonal and stress signaling. Curr. Opin. Plant Biol. 5:408-414.

Wang, Y., Bouwmeester, K., van de Mortel, J. E., Shan, W., and Govers, F. 2013. A novel Arabidopsis-oomycete pathosystem: Differential interactions with Phytophthora capsici reveal a role for camalexin, indole glucosinolates and salicylic acid in defence. Plant Cell Environ. 36: 1192-1203.

Widmer, T. L., Graham, J. H., and Mitchell, D. J. 1998. Histological comparison of fibrous root infection of disease-tolerant and susceptible citrus hosts by Phytophthora nicotianae and P. palmivora. Phytopathology 88: 389-395.

Wu, J., Alférez, F. M., Johnson, E. G., and Graham, J. H. 2018. Up-regulation of PR 1 and less disruption of hormone and sucrose metabolism in roots is associated with lower susceptibility to 'Candidatus Liberibacter asiaticus'. Plant Pathol. 67:1426-1435.

Zhang, X., Francis, M. I., Dawson, W. O., Graham, J. H., Orbović, V., Triplett, E. W., and Mou, Z. 2010. Over-expression of the Arabidopsis NPR1 gene in citrus increases resistance to citrus canker. Eur. J. Plant Pathol. 128:91-100. 